\title{
Temporal and spatial scales of the Yellow Sea thermal variability
}

\author{
Peter C. Chu and Susan K. Wells \\ Department of Oceanography, Naval Postgraduate School, Monterey, California \\ Steven D. Haeger, Carl Szczechowski, and Michael Carron \\ Naval Oceanographic Office, Stennis Space Center, Missıssippi
}

\begin{abstract}
This paper presents an analysis on the space/time statistical thermal structure in the Yellow Sea from the Navy's Master Observation Oceanography Data Set during 1929-1991. This analysis is for the establishment of an Optimum Thermal Interpolation System of the Yellow Sea (a shallow sea), for the assimilation of observational data into coastal $\sigma$ coordinate ocean prediction models (e.g., the Princeton Ocean Model), and for the design of an optimum observational network. After quality control the data set consists of 35,658 profiles. Sea surface temperatures at $50 \%$ and $80 \%$ water depths are presented here as representing the thermal structure of surface, middepth, and nearbottom layers. In the Yellow Sea shelf the temporal and spatial signals fluctuate according to the Asian monsoon. Variation of surface forcing from winter to summer monsoon season causes the change of the thermal structure, including the decorrelation scales. Our computation shows that the seasonal variation of the surface horizontal decorrelation scale is around $90 \mathrm{~km}$ from $158 \mathrm{~km}$ in winter to $251 \mathrm{~km}$ in summer and the seasonal variation of the surface temporal decorrelation scale is around 2.4 days from 14.7 days in winter to 12.3 days in summer. The temporal decorrelation scale increases with depth in both summer (evident) and winter (slight). The near-bottom water $(\sigma=0.8)$ has the longest temporal scale in summer, which could be directly related to the existence of the Yellow Sea Cold Water throughout the summer in the middle of the Yellow Sea. The temporal and spatial decorrelation scales obtained in this study are useful for running optimum interpolation models and for designing an optimum observational network. The minimum sampling density required to detect thermal variability in the Yellow Sea shelf would be $50-80 \mathrm{~km}$ and 4-6 day intervals per temperature measurement with the knowledge that the subsurface features will also be adequately sampled.
\end{abstract}

\section{Introduction}

Various ocean systems such as fronts, eddies, and water masses have different temporal and spatial scales. These scales feature a system's life span and spatial extent both horizontally and vertically. Horizontal scales for temperature fields in deep ocean basins have been extensively studied; for example, White et al. [1982] identified spatial correlation scales in the western Pacific of about $600 \mathrm{~km}$ in the tropics (south of $17.5^{\circ} \mathrm{N}$ ) and 300 $\mathrm{km}$ in the subtropics (north of $17.5^{\circ} \mathrm{N}$ ), while Ozsoy et al. [1989] found the spatial scales to be $200-250 \mathrm{~km}$ in the Levantine Basin of the Mediterranean Sea.

Temporal and horizontal scales in the continental shelf, and especially in the region of freshwater influence, have been less studied. One major reason is that due to great depths the deep ocean temperature profiles tend to follow the pattern of mixed layer, a thermocline, and a deeper layer slowly decreasing in temperature with depth. Shallow water does not consistently mimic this pattern. It may range from the classical profile to completely isothermal. The coastal water is largely affected by bathymetry, river runoff, internal waves, and tides. Therefore the temporal and horizontal scales are also under the strong

This paper is not subject to U.S. copyright. Published in 1997 by the American Geophysical Union.

Paper number $96 \mathrm{JC} 03428$. influence of these forcing factors and should have different vertical structure from the deep water [Wells, 1994]. For deep waters the vertical variations of the temporal and horizontal scales are usually obtained from the temperature fields at different depths (e.g., 100, 200, and $300 \mathrm{~m}$ from White et al. [1982]) or from the sea surface temperature (SST) field and the depth of certain temperature (e.g., depth of $20^{\circ} \mathrm{C}$ from Sprintall and Meyers [1991]). Neither scheme is practical for the Yellow Sea region because of a single-layer structure appearing in winter, which makes the depth of certain isotherm nonrepresentative for the subsurface thermal fields, and because of a strong influence of horizontally varying bathymetry on the shallow water, which causes the temperature fields at different depths to be nonrepresentative of subsurface fields. For deep water these depths are easily determined (Figure 1a). However, for shallow water with a sloping bottom, any chosen depths will lead to some areas (hatched area in Figure 1b) not covered by any submodels. Therefore no climatology can be constructed for these areas. In order to solve this problem, we use $\sigma$ surfaces

$$
\sigma=-z / H
$$

to build up climatology and statistical structure. Here $H$ is the water depth, and $z$ is the vertical coordinate. Midwater properties are represented by $\sigma=0.5$, and the near-bottom water 
(a)

\begin{tabular}{c}
\hline top model \\
\hline middle model
\end{tabular}

(c)

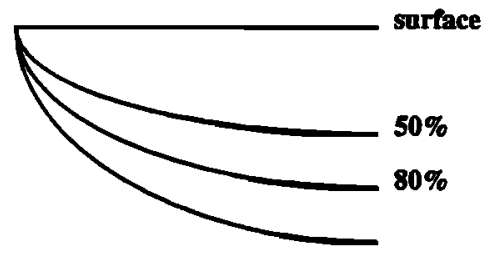

Figure 1. Depths for building temperature climatology: (a) horizontal levels for deep water, (b) horizontal levels for continental shelf, and (c) bottom following levels.

features are portrayed by $\sigma=0.8$ (Figure 1c). The analysis on the $\sigma$ coordinate system is a benefit for initializing popular $\sigma$ coordinate coastal models, such as the Princeton Ocean Model [Blumberg and Mellor, 1987]. However, the analysis on the $\sigma$ coordinate system has disadvantage during weakly forced and stratified periods. The deeper $\sigma$ levels will be within the mixed layer environment in shoal areas and below the mixed layer in the deeper portions of the basin.

The U.S. Navy's Master Oceanographic Observation Data Set (MOODS) has approximately 35,658 profiles (during 1929-1991) for the Yellow Sea shelf. After climatology has been established from these profiles, temperature anomalies are computed by subtracting the climatology from the observations. An autocorrelation function (ACF) is then defined by

$$
\eta(l)=\frac{1}{s^{2}} \int^{L} T^{\prime}\left(l_{0}\right) T^{\prime}\left(l_{0}+l\right) d l_{0}
$$

where $T^{\prime}$ is the temperature anomaly, $l_{0}$ denotes the independent space/time vectors defining the location of points in a sampling space $L$, and $l$ is the space/time lag and $s^{2}$ is the variance. Here $\eta$ is computed by paring the anomalies into bins depending upon their separation in space/time, $l$. The values of $\eta$ will be obtained from calculating the correlation coefficient for all the anomaly pairs in each bin which will be constructed for the combination of different lags.

\section{Characteristics of the Yellow Sea}

The Yellow Sea is the middle section of a continental sea system (Figure 2). To the north is the Bohai Sea and to the south are the East China Sea and the western Pacific beyond. It lies between China and the Korea Peninsula and covers an area of approximately $295,000 \mathrm{~km}^{2}$. There are four major rivers that flow into it. The Yangtze River is located to the southwest, the Yellow River and the Liao River to the north, and the Han River to the east. While the Yellow Sea covers a relatively large area, it is uniformly shallow. The water depth over most of the area is less than $50 \mathrm{~m}$. The deepest water is confined to a north-south oriented trench paralleling the Korean coastline in the central portion with a maximum depth of $90 \mathrm{~m}$. The bottom slopes from $20 \mathrm{~m}$ near the China coast to its southern boundary, the shelf break, at $150 \mathrm{~m}$. Within $50 \mathrm{~km}$ of the Korean coastline the average water depth is $20 \mathrm{~m}$.

The Yellow Sea lies within the Asian monsoon circulation area and experiences hot, humid summers and cold, dry winters. In winter the Yellow Sea is dominated by the cold northerly wind associated with the Siberian high (Figure 3a). The wind speed reaches a maximum in February with a value of 35 $\mathrm{m} / \mathrm{s}$ near the central portion and of $28 \mathrm{~m} / \mathrm{s}$ over the whole Yellow Sea [Elms, 1990]. The northerly wind bursts create a southward sea level gradient that forces bottom water to flow northward in spurts along the Yellow Sea trough [Hsueh, 1988]. The January surface air temperature (SAT) varies from $0^{\circ}$ to $8^{\circ} \mathrm{C}$ in the Yellow Sea (Figure $4 a$ ), roughly $2^{\circ}-6^{\circ} \mathrm{C}$ cooler than SST. The Yellow Sea surface loses heat to the atmosphere. The upward buoyancy flux at the air-ocean interface (thermal forcing), together with the strong wind stress (mechanical forcing), generates turbulence and mixes the surface water with the deeper water. The mixed layer is at its deepest (it usually fills the whole water column) during winter owing to both convection and wind mixing by the strong northeast monsoon winds. The change of seasons begin in March when the surface air temperatures are $5^{\circ} \mathrm{C}$ warmer than in February. Rapid weakening of the Siberian high progresses into April. In late April the atmospheric polar front has moved northward toward Korea with warm, moist air following behind. Numerous front-driven events occur, making late April and May

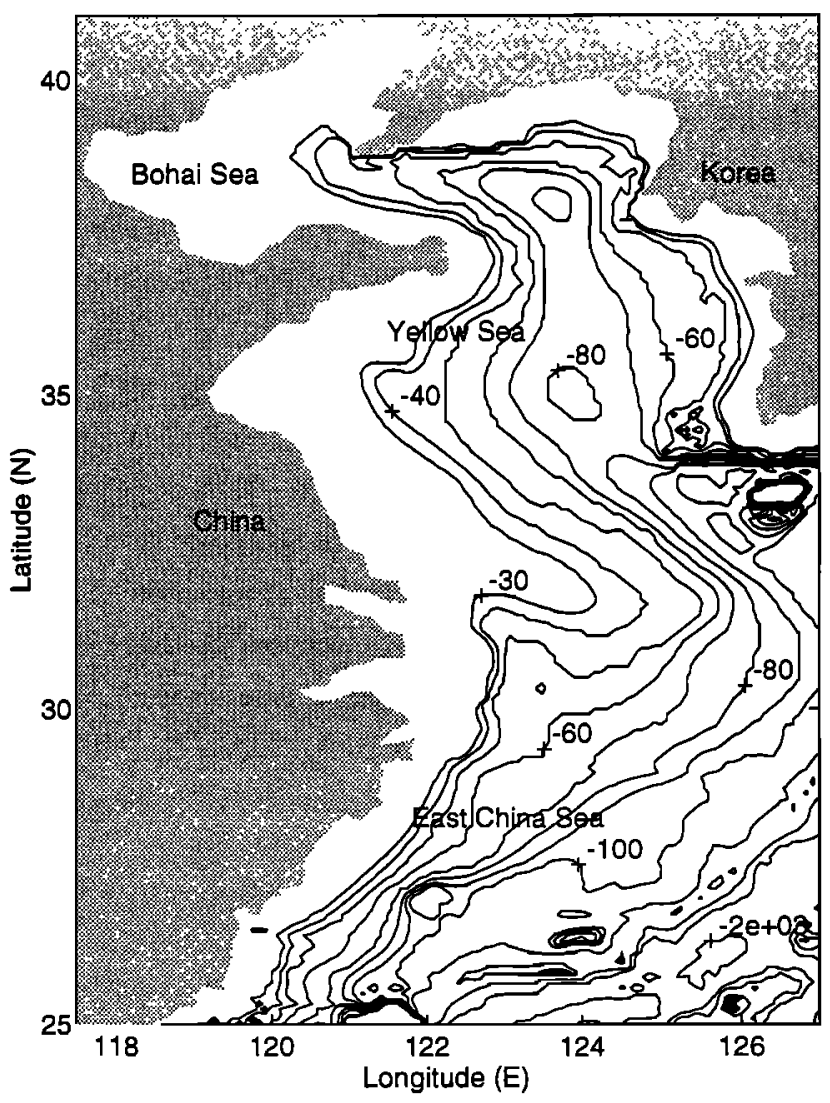

Figure 2. Bottom topography of the Yellow Sea and the surrounding regions. The data are obtained from the U.S. Naval Oceanographic Office DBDB5 world bathymetry database. Depths are in meters. 
highly variable in terms of winds, clouds, and precipitations. The Yellow Sea surface quickly transits from winter to spring temperatures with an average increase of $10^{\circ} \mathrm{C}$.

In late May and early June the atmospheric low-pressure system begins to form in the north of the Yellow Sea and to migrate toward the west over Manchuria in late June, setting up the southwest monsoon that dominates the summer months. The Manchuria Low, associated with the atmospheric high-pressure system in the southeast (the Bonin High), produces southerly winds carrying warm, moist air over the Yellow Sea (Figure $3 \mathrm{~b}$ ). The summer SAT is quite uniform and around $24^{\circ}-26^{\circ} \mathrm{C}$ (Figure $4 \mathrm{~b}$ ). It is usually $1.5^{\circ}-2^{\circ} \mathrm{C}$ warmer than SST [Van Loon, 1984]. The warm air and the strong downward net radiation cause downward heat flux and stabilize the upper layer of the water and cause the surface mixed layer to shoal. Associating with the shallow mixed layer a closed surface cyclonic circulation occurs above the thermocline, which is about $13 \mathrm{~m}$ in August, and may reach a speed of $15 \mathrm{~cm} / \mathrm{s}$ [Bartz, 1972]. Below the thermocline, there is a cold water mass, commonly referred to as the Yellow Sea Cold Water (YSCW) mass, that

(a)

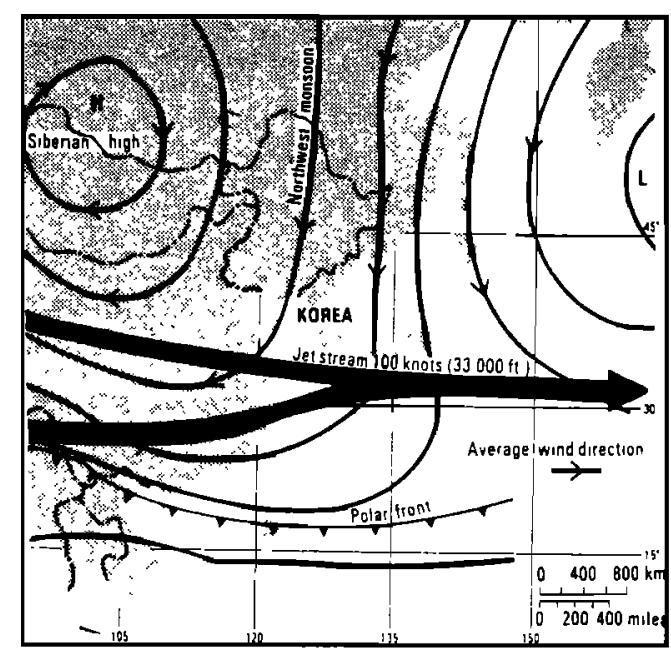

(b)

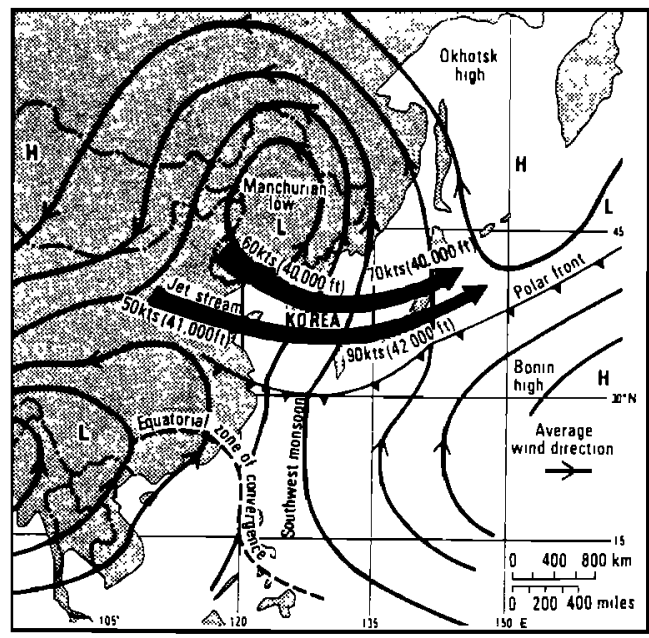

Figure 3. Mean atmospheric surface circulations in the vicinity of the Yellow Sea for (a) February and (b) June [from Langhill, 1976].
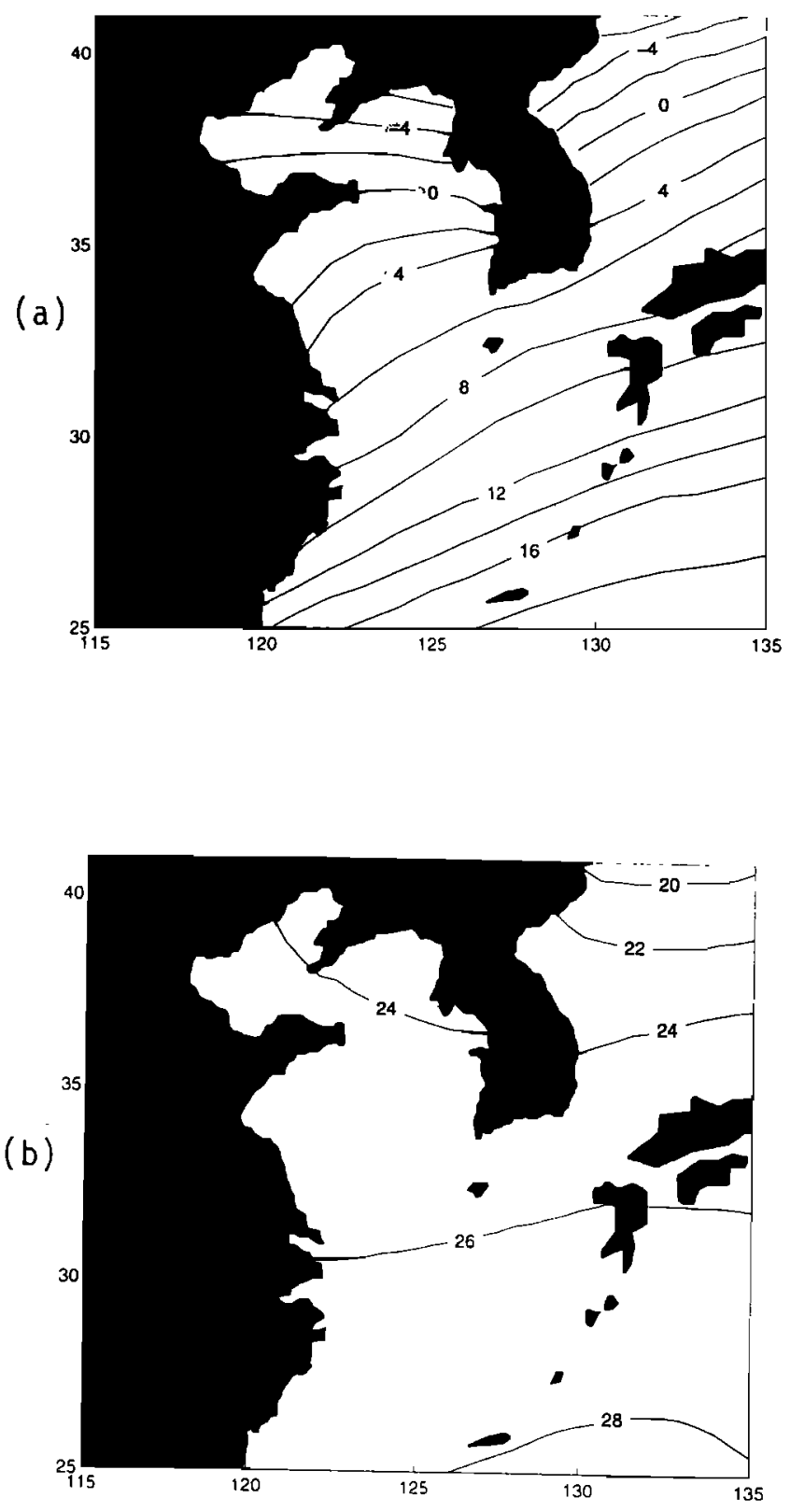

Figure 4. Mean surface air temperature in the vicinity of the Yellow Sea for (a) January and (b) July.

remains unchanged and nearly motionless throughout the summer [ $\mathrm{Li}$ and Yuan, 1992]. October is the beginning of the transition back to winter conditions. The southerly winds have weakened, letting the sea surface slope reestablish toward the winter pattern again. The SST steadily decreases from October to January.

\section{The MOODS Data Set}

The temperature profiles (1929-1991) used for this study were taken from MOODS. There are approximately 50,000 temperature profiles located between $119^{\circ}-128^{\circ} \mathrm{E}$ and $25^{\circ}$ $40^{\circ} \mathrm{N}$, which encompass the Yellow Sea and the northern East China Sea. The data were screened to restrict the data set to those profiles that are located on the continental shelf. This reduces the data set to 35,658 profiles (Figure 5). To investigate the seasonal variation of the temporal and spatial scales, 


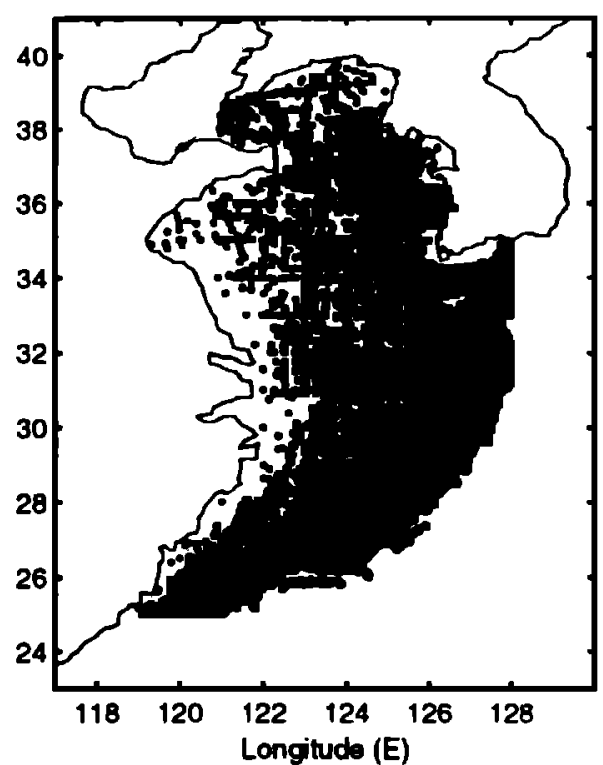

Figure 5. Distribution of MOODS profiles in this study.

the database was binned into four seasons. The seasons were defined according to the convention of the Naval Oceanographic Office for the Yellow Sea. January, February, and March constitute winter; April, May, and June constitute spring; July, August, and September constitute summer; and October, November, and December constitute fall. Table 1 shows the partition of the data; winter has the least profiles and summer has the most.

The main limitation of the MOODS data is their irregular distribution in time and space. Certain periods and areas are over sampled, while others lack enough observations to gain any meaningful insights. Vertical resolution and data quality are also highly variable depending much on instrument type and sampling expertise. There is a data sparse area: the eastern coastal region of China (Figure 5). The period of 1963-1977 is found to have relatively large number profiles, averaging 315 per season. An example of temporally uneven distribution can be seen from Figure 6, which indicates a number of temperature observations during January-June 1977. There are frequent 15-20 day gaps of no observations in the whole Yellow Sea. Spatial and temporal irregularities along with the lack of data in certain regions must be carefully weighted in order to avoid statistically induced variability. Originally, it was hoped that there would be sufficient data to compute horizontal and temporal decorrelation scales on a yearly basis and to determine a trend. After analyzing the location and histogram of the data, it was obvious that statistically significant results cannot be obtained on a yearly basis. Analysis was done on a mean seasonal basis using the data for all years.

Table 1. Number of Temperature Profiles in the Database for Each Season

\begin{tabular}{lc}
\hline Season & $\begin{array}{c}\text { Number of } \\
\text { Profiles }\end{array}$ \\
\hline Winter & 7391 \\
Spring & 9868 \\
Summer & 9915 \\
Fall & 8484 \\
\hline
\end{tabular}

\section{Establishment of Seasonal Climatology}

Building climatological fields from the MOODS database is not a straightforward task, and in shallow water the problems are magnified. Most of the problems are related to lack of data. Without enough data, individual observations force artificial gradients to occur. In addition, the sloping bottom poses difficulties with interpolating techniques. If the temperature values need to be unbiased, an appropriate background field (seasonal climatology) must be subtracted. Three major steps were used in establishing the seasonal temperature climatology: (1) binning the data seasonally, (2) interpolating the temperature profiles into the desired depth, and (3) gridding the temperature with the MInimum curvature SPline (MISP) Interpolator algorithm developed at the Naval Oceanographic Office. This algorithm is similar to the Cubic Spline Interpolator (e.g., as given by in MATLAB [1992]). During the MISP interpolation we apply a low-pass filter to the observed temperature values at each $\sigma$ level of interest. That is, the interpolated background temperature at a grid was a weighted linear combination of the adjacent measured values at the same $\sigma$ level. The choice of the decay scale for the Gaussian weights of the filter was somewhat arbitrary except that we wanted it to be much longer than the decorrelation scale of ACF. We used a decay scale of $5^{\circ}$ for the filter weights which gave a very smooth background field.

The mean temperature field at $\sigma=0$ (Figure 7) is more uniform horizontally in summer than in winter. The mean temperature fields at $\sigma=0.5$ (Figure 8) and $\sigma=0.8$ (Figure 9) mimic each other from season to season. The only difference is that the temperature reduces near $2{ }^{\circ} \mathrm{C}$ in summer from $\sigma=0.5$ to $\sigma=0.8$, representing $12-24 \mathrm{~m}$ in depth change (Figure 2). The winter subsurface $(\sigma=0.5,0.8)$ mean temperature fields closely mirror the mean SST field (single layer). The summer subsurface mean temperature fields are quite different from the mean SST (multilayer). Furthermore, the summer mean SST field is quite uniform horizontally in the Yellow Sea shelf, whereas the subsurface temperature fields show a cold core in the central bottom of the Yellow Sea, i.e., YSCW. In winter it merges with the surface water, but from April to November it

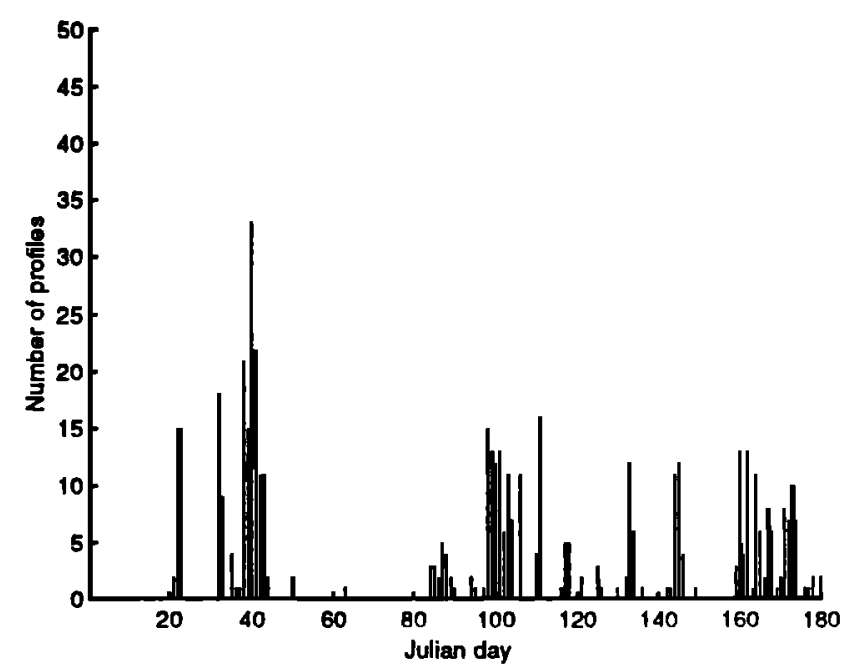

Figure 6. Number of temperature profiles in the Yellow Sea shelf during January-June 1977. This is typical data density in any given 6 months during 1963-1977. 
(a) Winter

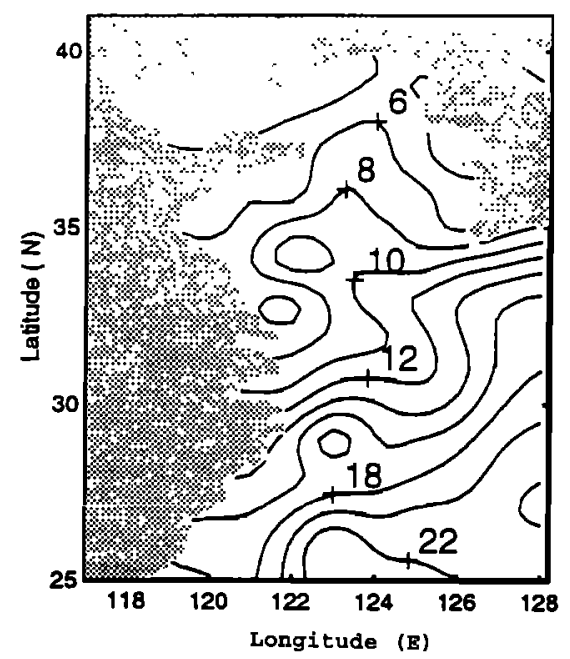

(b) Summer

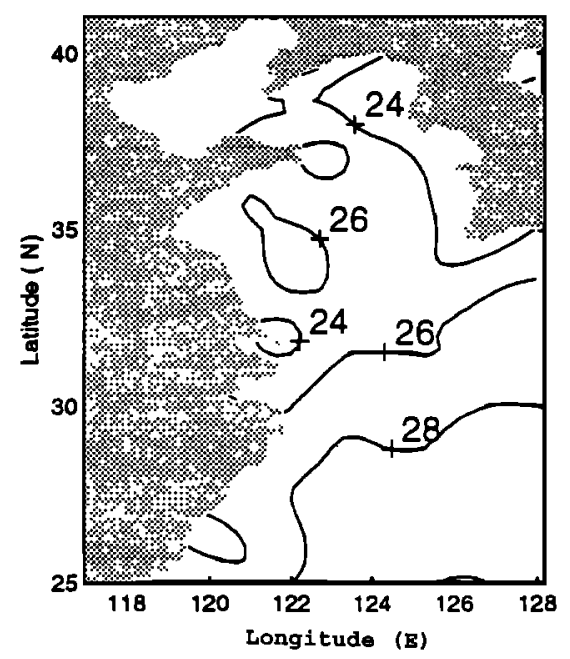

Figure 7. Surface $(\sigma=0)$ mean temperature field during (a) winter and (b) summer.

is a distinct water mass with temperature of $4^{\circ}-5^{\circ} \mathrm{C}$. During summer the overlying waters are $10^{\circ}-15^{\circ} \mathrm{C}$ warmer.

\section{Space/Time Sorting}

At present the spatial and temporal scales are important input data for the U.S. Navy's Optimum Thermal Interpolation System (OTIS) model; that is, the user should provide the values of these scales before running the OTIS model. What are these values for the Yellow Sea? We should use the most extensive MOODS data to obtain these scales. On the basis of the bowl-type bathymetry (Figure 2), Guan [1994] suggested that the basin may be treated as an isolated system. Therefore it is reasonable to assume that the temperature ACFs inside the Yellow Sea are isotropic; that is, ACFs only depend on the distance between two temperature locations. The major reason for using horizontal isotropicity here is the data sparseness (Table 1). If we do not use this assumption, the number of bins becomes very large; for example, it will be 27,000 if each of the temporal and spatial ( $x$ and $y$ ) lags has 30 bins. It is difficult to obtain meaningful statistics.

For each observation at certain $\sigma$ levels $(\sigma=0,0.5,0.8$, , $T_{o}^{(\sigma)}$, find the closest grid point climatological value $\bar{T}_{l}^{(\sigma)}$ and compute the anomaly $T_{(}^{(\sigma) \prime}$, by subtracting $\bar{T}_{l}^{(\sigma)}$ from $T_{O}^{(\sigma)}$, i.e., $T_{O}^{(\sigma) \prime}=T_{O}^{(\sigma)}-\bar{T}_{O}^{(\sigma)}$. Every individual anomaly, $T_{O}^{(\sigma) \prime}$, is paired with the other data points, $\hat{T}_{\sigma}^{(\sigma)}{ }^{\prime}$, within the four seasons. The temporal and spatial differences or lags are calculated between the two anomalies. The anomaly pair $\left(T_{6}^{(g)}\right)^{\prime}$, $\left.\hat{T}_{\left({ }^{\prime}\right.}^{(r) \prime}\right)$ is then placed in the corresponding temporal (with increment $\Delta t=1$ day) and spatial (with increment $\Delta r=10$ $\mathrm{km})$ lag bin. If the lags are within $\Delta r_{0}(5 \mathrm{~km})$ and $\Delta t_{0}(0.5$ day $)$, the corresponding pair is placed into bin $(0,0)$. If the horizontal lag is between $m \Delta r-\Delta r_{0}$ and $m \Delta r+\Delta r_{0}$ and the temporal lag is between $n \Delta t-\Delta t_{0}$ and $n \Delta t+\Delta t_{0}$, the pair is placed into the bin $(m, n)$. The pair-number distributions, $P(m, n)$, for the four seasons are depicted in Figure 10 . We see some uneven distribution in the temporal and spatial bins. (a) Winter

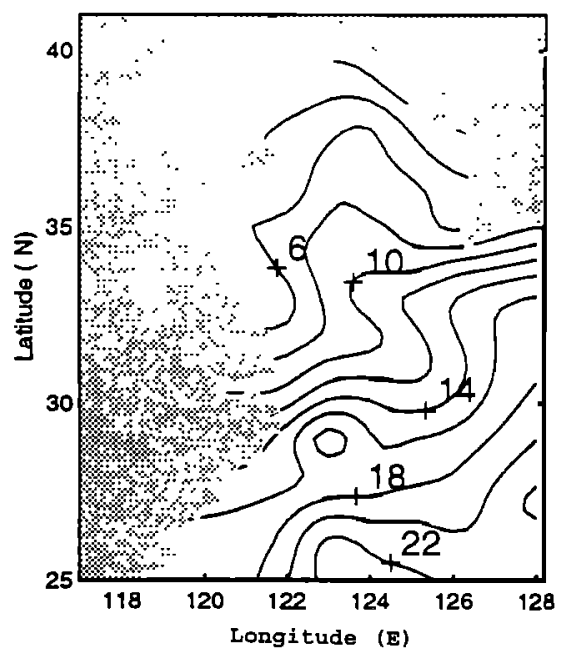

(b) Summer

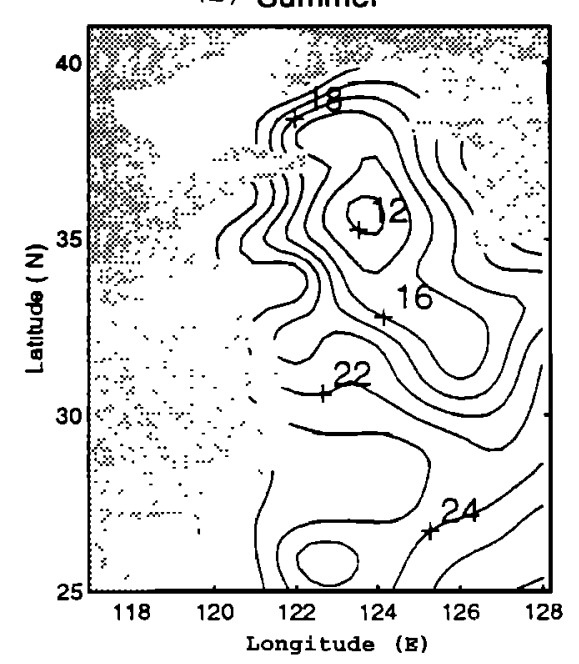

Figure 8. Middepth $(\sigma=0.5)$ mean temperature field during (a) winter and (b) summer. 


\section{(a) Winter}

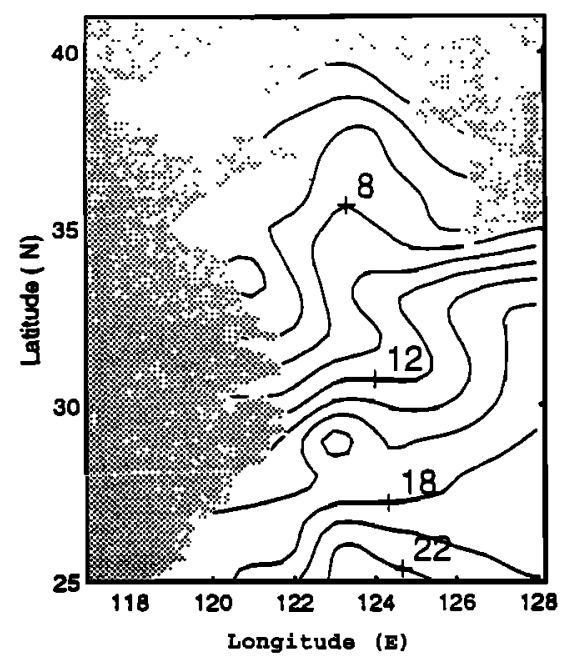

(b) Summer

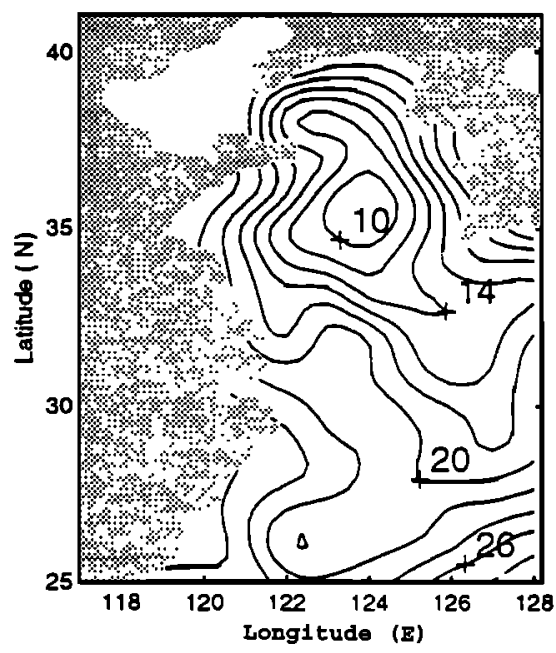

Figure 9. Near-bottom ( $\sigma=0.8)$ mean temperature field during (a) winter and (b) summer.

Almost everywhere, $P(m, n)$ is equal to or more than 500 . The maximum $P(m, n)$ is located in bins with near 1-2 day temporal lags and $80-120 \mathrm{~km}$ spatial lags.

\section{Autocorrelation Functions}

\subsection{ACF Estimation}

After the anomaly pairs have been spatially and temporally sorted, the ACF value for each bin $(m, n)$ is computed by

$$
\eta^{(\sigma)}(m, n)=\frac{\sum_{\operatorname{bin}(m, n)} T_{O}^{(\sigma) \prime} \hat{T}_{O}^{(\sigma) \prime}}{\sum_{\operatorname{bin}(m, n)}\left(T_{O}^{(\sigma) \prime}\right)^{2}}
$$

which varies with the spatial and temporal lags $(m, n)$ and level $\sigma$. Surface ACFs, $\eta^{(0)}(m, n)$, of both winter (Figure 11a) and summer (Figure 11b) are characterized by decreasing amplitude with longer temporal and spatial lags.
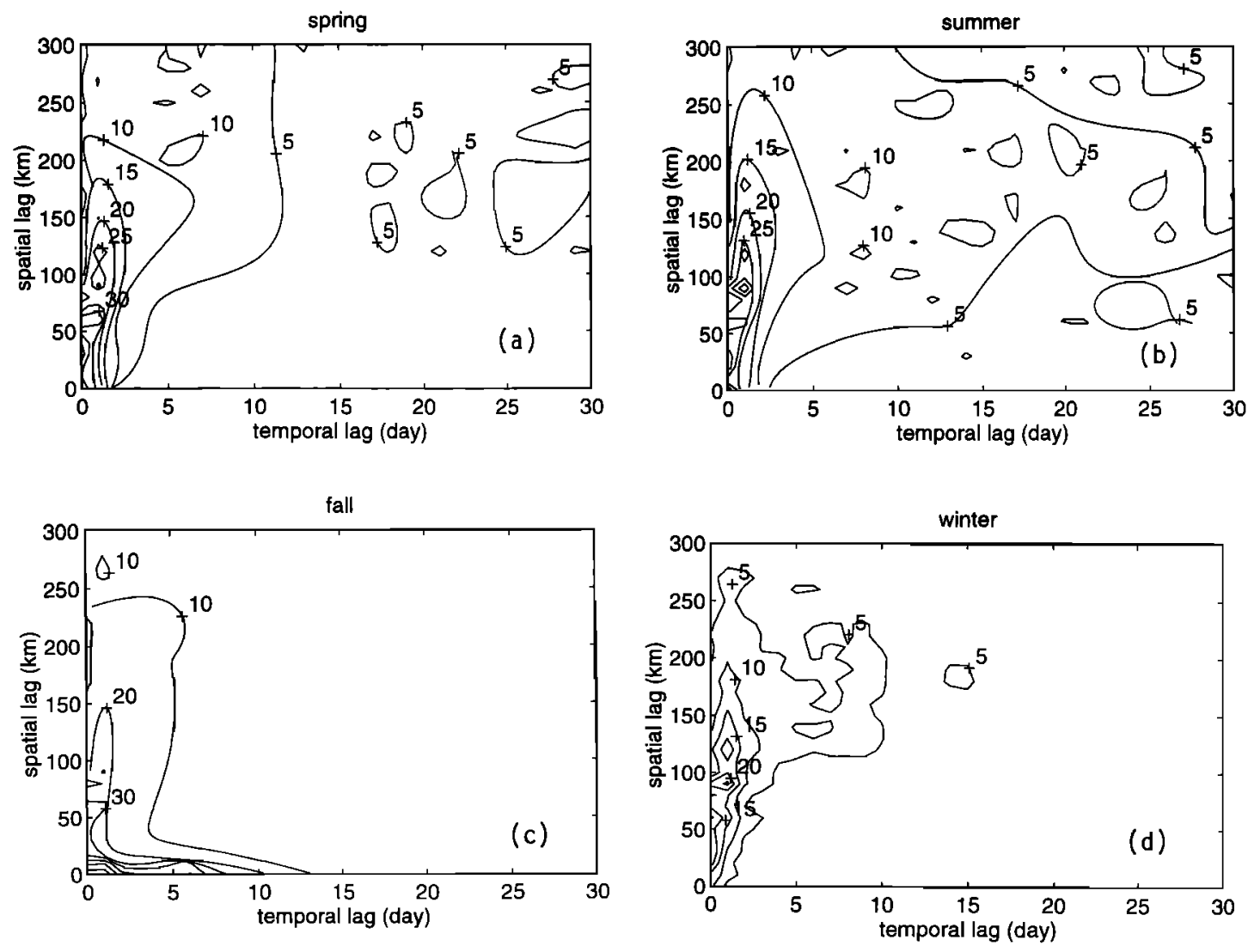

Figure 10. The pair-number (in 100) distribution in the $(m, n)$ space for (a) spring, (b) summer, (c) fall, and (d) winter. 


\subsection{The $t$ Test for the ACF Estimation}

Equation (3) indicates that the computed ACF in the bin $(m, n)$ is in fact the estimation of the correlation coefficient of pairs in that bin. A $t$ value for verifying the significance of a sample correlation coefficient is given by [Walpole and Myers, 1989]

$$
t=\frac{\eta \sqrt{P-2}}{\sqrt{1-\eta^{2}}}
$$

which is a value of the statistic $T$ having a $t$ distribution with $P-2$ degree of freedom. Using $\alpha$ as the level of significance, a criterion $\eta_{\alpha}$ is obtained

$$
\eta_{\alpha} \equiv \frac{t_{\alpha}}{\sqrt{P-2+t_{\alpha}^{2}}}
$$

The criterion $\eta_{\alpha}$ has a strong seasonal variation (Figure 12) due to the change of pair numbers $P(m, n)$. The criterion $\eta_{\alpha}$ is much smaller for most bins in summer than in winter.

When $\eta^{(\sigma)}(m, n)>\eta_{\alpha}$, the estimated ACF is significant on the level of $\alpha$. Since both $\eta^{(\sigma)}(m, n)$ and $\eta_{\alpha}$ have seasonal variations, the significance of the ACF estimation should also change with seasons. The significant surface ACF estimation $(\alpha=0.10)$ is limited to the left lower corner of the $(\tau, r)$ plane with $\tau<15$ day and $r<200 \mathrm{~km}$ in winter (Figure 13a) and occupies nearly the whole left part of the $(\tau, r)$ plane with $\tau<$ 20 day in summer (Figure 13b). Such a seasonal variability in significant ACF estimations leads to a significant difference in statistical parameters such as decorrelation scales.
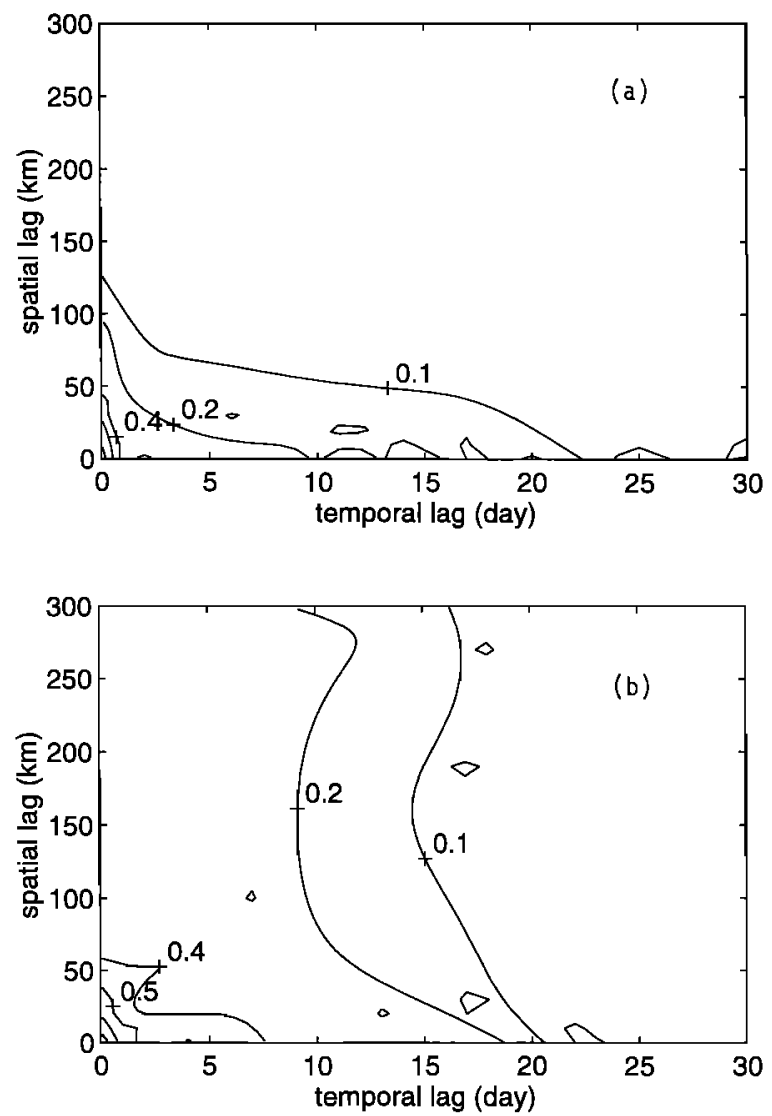

Figure 11. Dependence of surface $\mathrm{ACF}$ on spatial and temporal lags $(m, n)$ for (a) winter and (b) summer.
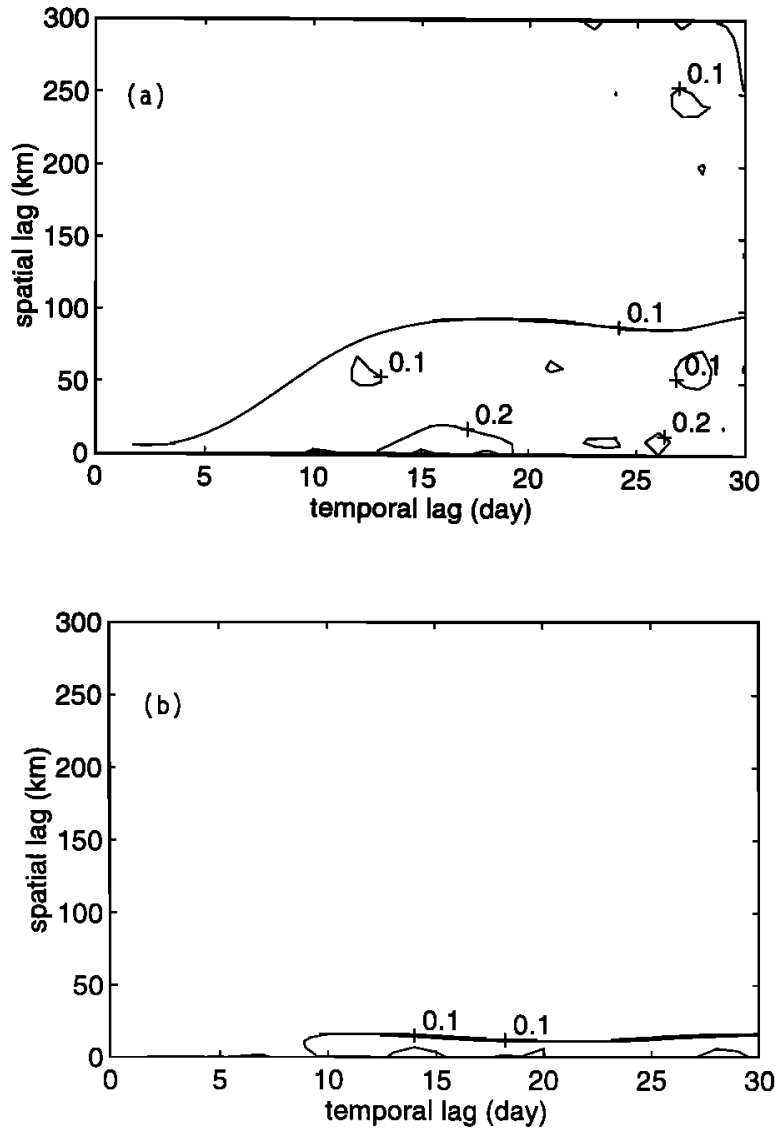

Figure 12. Criterion (0.10 significant level) for surface ACF estimation: (a) winter and (b) summer.

\subsection{Signal-to-Noise Ratio}

The measured variance $s^{2}$ of the thermal fields is separated into signal and noise whereby

$$
s^{2}=s_{s}^{2}+s_{n}^{2}
$$

The noise variance is brought on from two sources, geophysical and instrumentation errors. Here the geophysical error is unresolved thermal variability with scales smaller than the typical timescales and space scales between two temperature profiles. In this study the unresolved scales are 0.5 day and $5 \mathrm{~km}$. The ACF value at the first bin $(0,0)$ does not represent the correlation between profiles paired by themselves and therefore does not equal 1. Following Sprintall and Meyers [1991], the signal-to-noise ratio is computed by

$$
\lambda \equiv \frac{s_{s}}{s_{n}}=\sqrt{\frac{\eta(0,0)}{1-\eta(0,0)}}
$$

The larger the $\lambda$ is, the less geophysical error existed. If $\eta(0,0)=1$, there is no noise, $\lambda=\infty$, and if $\eta(0, \mathbf{0})=0$, there is no signal. If $\lambda>2$, the ratio of the signal variance, $s_{s}^{2}$, to the noise variance, $s_{n}^{2}$, is greater than 4 , which was considered quite good conditions by White et al. [1982] and Sprintall and Meyers [1991].

\subsection{Temporal Dependence of ACFs}

The temporal dependence of $\mathrm{ACF}, \eta^{(\sigma)}(m, n)$, can be easily discussed by $\eta-n$ curves at several different spatial lags, e.g., $m=0$ ("no lag"), $m=1$ (10-km lag), and $m=15$ 

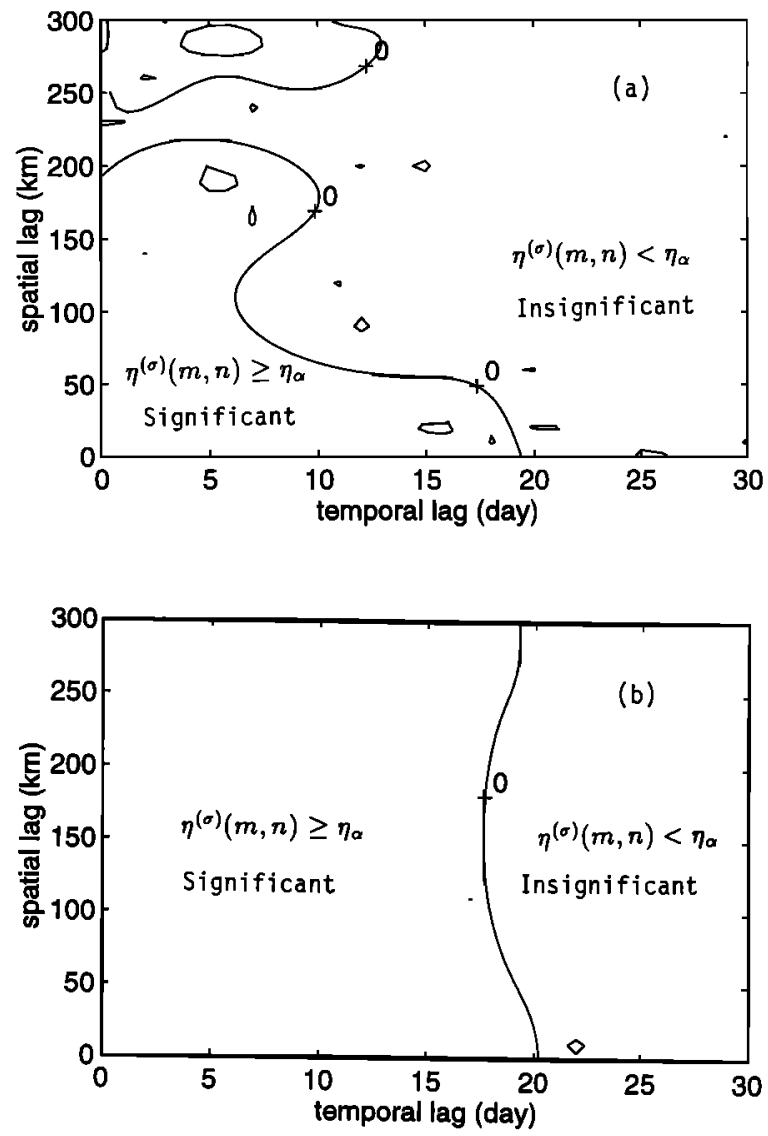

Figure 13. Significant surface ACF estimation on level of 0.10 for (a) winter and (b) summer.

(150-km lag). These curves were plotted for different seasons and three depths $(\sigma=0,0.5,0.8)$ in order to see the seasonal and vertical variations. The three winter curves, $\eta^{(\sigma)}(0, n)$, $\eta^{(\sigma)}(1, n)$, and $\eta^{(\sigma)}(15, n)$, are plotted for the surface, $\sigma=0$ (Figure 14a), the middepth, $\sigma=0.5$ (Figure 14b), and the near bottom, $\sigma=0.8$ (Figure 14c). We notice from Figure 12a that $\eta^{(0)}(15, n)$ is significant only if the temporal lag is smaller than 10 days (i.e., $n<10$ ). The three summer curves, $\eta^{(\sigma)}(0, n), \eta^{(\sigma)}(1, n)$, and $\eta^{(\sigma)}(15, n)$, are plotted for the surface, $\sigma=0$ (Figure 15a), the middepth, $\sigma=0.5$ (Figure $15 \mathrm{~b}$ ), and the near bottom, $\sigma=0.8$ (Figure 15c).

The ACFs have the following features:

1. Its temporal variability weakens as the spatial lag increases and becomes extremely small (near constantly low ACF) at the spatial lag $m=15(150 \mathrm{~km})$ except for the summer surface field (Figure 15a), where ACF decreases quasi-linearly with the time lag (dotted line in Figure 15a).

2. Its vertical variability is quite small during winter (Figures 14a, 14b, and 14c) and not so small during summer (Figures 15a, 15b, and 15c). This coincides with the single-layer structure in winter and the multilayer structure in summer (P. C. Chu et al., A feature model for the Yellow Sea shelf thermal structure, submitted to Journal of Geophysical Research, 1996) (hereinafter referred to as Chu et al., submitted manuscript, 1996).

3. During summer the ACF's temporal variability weakens with depth. The surface ACF shows a fast reduction with time lag $n$ (Figure 15a). The midwater $(\sigma=0.5)$ ACF has slower reduction than the surface as $n$ increases (Figure 15b). The near-bottom ( $\sigma=0.8)$ ACF fluctuates around certain values ( 0.5 for no spatial lag, 0.28 for $10-\mathrm{km}$ lag, and almost 0 for 150 $\mathrm{km}$ ) as $n$ increases (Figure 15c).

\subsection{Spatial Dependence of ACFs}

The spatial dependence of ACF, $\eta^{(\sigma)}(m, n)$, can be easily discussed by $\eta-m$ curves at several different temporal lags, e.g., $n=0$ ("no lag"), $n=1$ (1-day lag), and $n=15$ (15-day lag). These curves were plotted for different seasons and three depths $(\sigma=0,0.5,0.8)$ in order to see the seasonal and vertical variations. The three winter curves, $\eta^{(\sigma)}(m, 0), \eta^{(\sigma)}(m, 1)$, and $\eta^{(\sigma)}(m, 15)$, are plotted for the surface, $\sigma=0$ (Figure 16a), the middepth, $\sigma=0.5$ (Figure 16b), and the near bottom, $\sigma=0.8$ (Figure 16c). We notice from Figure 12a that $\eta^{(0)}(m, 15)$ is significant only if the spatial lag is smaller than $50 \mathrm{~km}$ (i.e., $m<5)$. The three summer curves, $\eta^{(\sigma)}(m, 0), \eta^{(\sigma)}(m, 1)$, and $\eta^{(\sigma)}(m, 15)$, are plotted for the surface, $\sigma=0$ (Figure $17 \mathrm{a}$ ), the middepth, $\sigma=0.5$ (Figure $17 \mathrm{~b}$ ), and the near bottom, $\sigma=0.8$ (Figure 17c).

The ACFs have the following features:

1. Its spatial variability weakens as the temporal lag increases and becomes very small (smaller than 0.2 ) at the time lag $n=15$ day except for the summer near-bottom field (Figure 17c), where the ACF's horizontal variability at $n=15$ days is quite close to that at $n=0$ (no time lag) and $n=1$ day lag, as shown in Figure 17c. This indicates that during summer the tidal effects (on the timescale less or equal than 1 day) are important for the Yellow Sea bottom thermal field.

2. Its vertical variability is quite small during winter (Figures 16a, 16b, and 16c) and not so small during summer (Figures 17a, 17b, and 17c). This coincides with the single-layer structure in winter and the multilayer structure in summer (Chu et al., submitted manuscript, 1996).

3. During summer the ACF's spatial variability strengthens with depth. The surface ACF shows a relatively weak reduction versus spatial lag (Figure 17a). The midwater $(\sigma=0.5) \mathrm{ACF}$ has a stronger reduction than the surface as the spatial lag increases (Figure 17b). The near-bottom $(\sigma=0.8)$ ACF has the strongest reduction versus spatial lag (Figure 17c).

\section{Temporal and Spatial Decorrelation Scales}

\subsection{The Gaussian Model}

The U.S. Navy's OTIS uses the Gaussian function to fit the ACF [Phoebus, 1988; Clancy, 1983]

$\hat{\eta}^{(\sigma)}(m, n)=\hat{\eta}^{(\sigma)}(0,0) \exp \left[-A_{\sigma}^{2}(m \Delta r)^{2}-C_{\sigma}^{2}(n \Delta \tau)^{2}\right]$

where $\hat{\eta}^{(\sigma)}(m, n)$ denotes the Gaussian fit of the ACF value (at level $\sigma$ ) in the bin with the spatial separation $m \Delta r$ and the temporal separation $n \Delta \tau$. $\Delta r$ and $\Delta \tau$ are increments for the space/time separation. $A_{\sigma}^{-1}$ and $C_{\sigma}^{-1}$ are horizontal and temporal decorrelation scales at different levels $\sigma$. The dominant space scales and timescales obtained from $\eta$ are important not only in determining sampling density but also for the optimum interpolation of the observed data. The U.S. Navy's OTIS runs everyday and combines real-time data, climatology, and predictions from ocean mixed layer models to represent an accurate picture of the ocean thermal structure on global and regional scales [Phoebus, 1988; Clancy, 1983]. Before running OTIS, the user should specify temporal and spatial scales $A_{\sigma}^{-1}$ and $C_{\sigma}^{-1}$, whose values are well determined in deep waters but not in continental shelves. Therefore determination of tempo- 


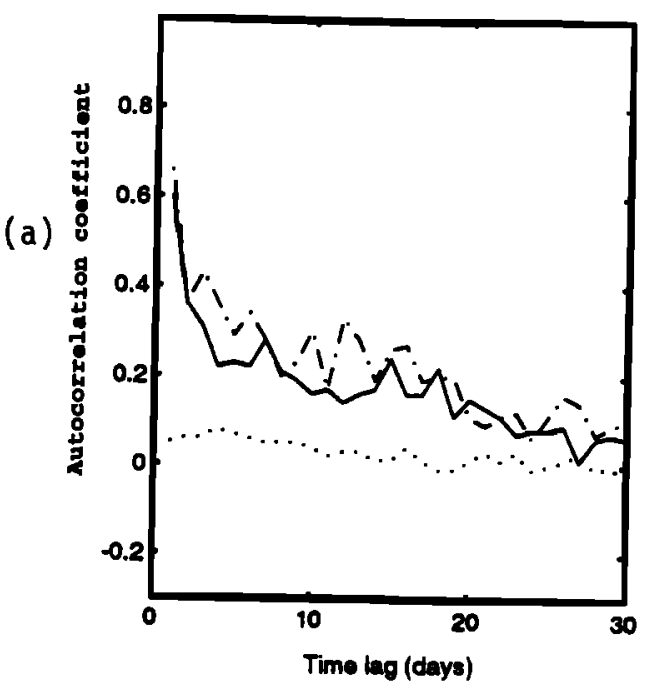

(b)

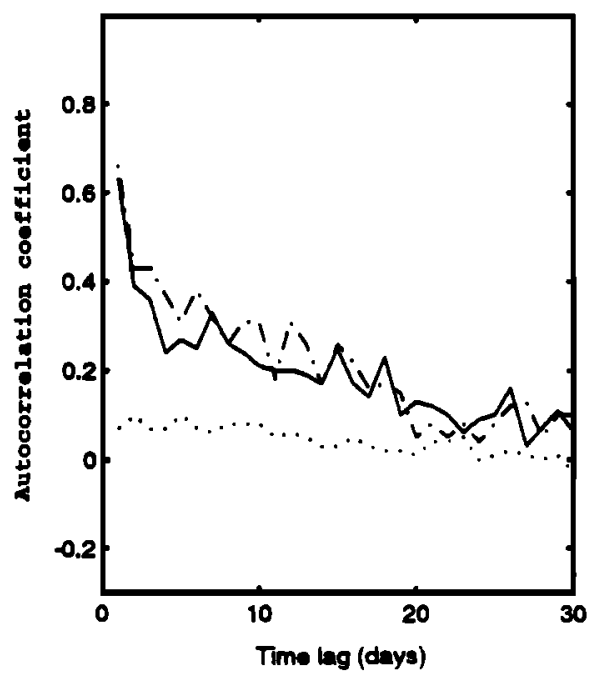

(c)

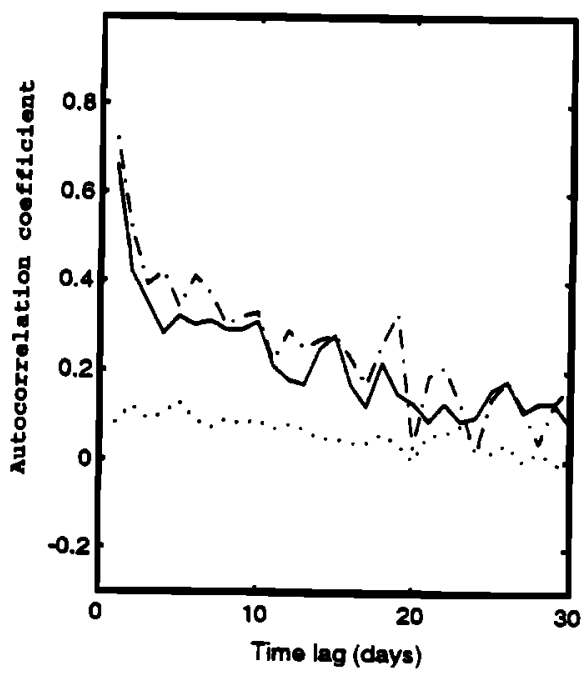

Figure 14. Winter temporal variation of ACF at different spatial lags: $m=0$ (no lag, dash-dotted line), $m=$ 1 (10-km lag, solid line), and $m=15(150 \mathrm{~km}$, dotted line) for three levels: (a) surface $(\sigma=0)$, (b) middepth $(\sigma=0.5)$, and (c) near bottom $(\sigma=0.8)$.

ral and spatial decorrelation scales is crucial for the continental shelf thermal interpolation.

\subsection{The $\boldsymbol{F}$ Test for the Gaussian Model}

One can test the hypothesis $H_{0}$ that the Gaussian model (6) is not significant by merely forming the ratio [Walpole and Myers, 1989]

$$
f=\frac{S S R / k}{S S E /(l-k-1)}
$$

where $k=2, l$ is the total number of bins in either spatial or temporal lags, and

$$
\begin{aligned}
S S R & \equiv \sum_{m} \sum_{n}\left[\ln \hat{\eta}^{(\sigma)}(m, n)-\overline{\ln \eta^{(\sigma)}}\right]^{2}, \\
S S E & \equiv \sum_{m} \sum_{n}\left[\ln \hat{\eta}^{(\sigma)}(m, n)-\ln \eta(m, n)\right]^{2}
\end{aligned}
$$

denoting a regression sum of squares and a residual mean square, respectively. When

$$
f>f_{\alpha}(k, l-k-1)
$$

we reject $H_{0}$. Here $f_{\alpha}(k, l-k-1)$ satisfies the $F$ distribution with $\nu_{1}=k, \nu_{2}=l-k-1$, and a confidence level of $\alpha$. The $f$ values for different levels and seasons are listed in Table 2. All the values of $f$ exceed the critical value (5.45) of the $F$ distribution for 2 and 28 degrees of freedom at $\alpha=0.01$. Therefore we can confirm that the Gaussian model is reasonable for the Yellow Sea thermal ACF.

\subsection{Seasonal Variabilities of the Decorrelation Scales}

The computed ACFs for different seasons and levels $(\sigma=0$, $0.5,0.8$ ) were then fitted to a Gaussian function of the form of (6) by the regression method, which leads to the spatial and temporal decorrelation scales, $A_{\sigma}^{-1}$ and $C_{\sigma}^{-1}$, respectively. Table 3 presents these decorrelation scales and signal-to-noise ratios for winter and summer.

The signal-to-noise ratios for both winter and summer are higher than that for the deep waters of the eastern equatorial Pacific, which is around 1.0 as reported by Sprintall and Meyers 


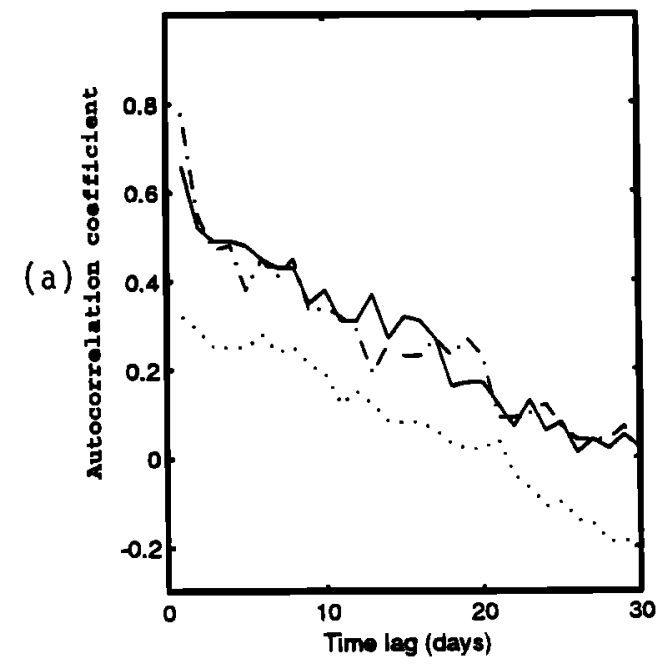

(b)

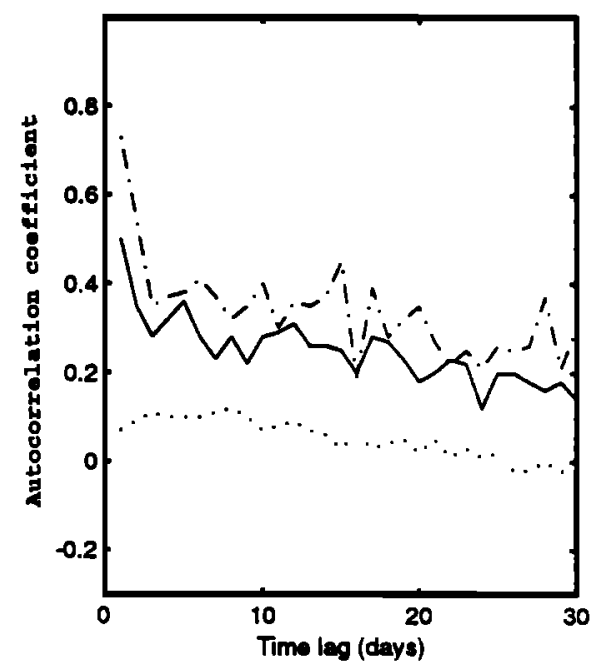

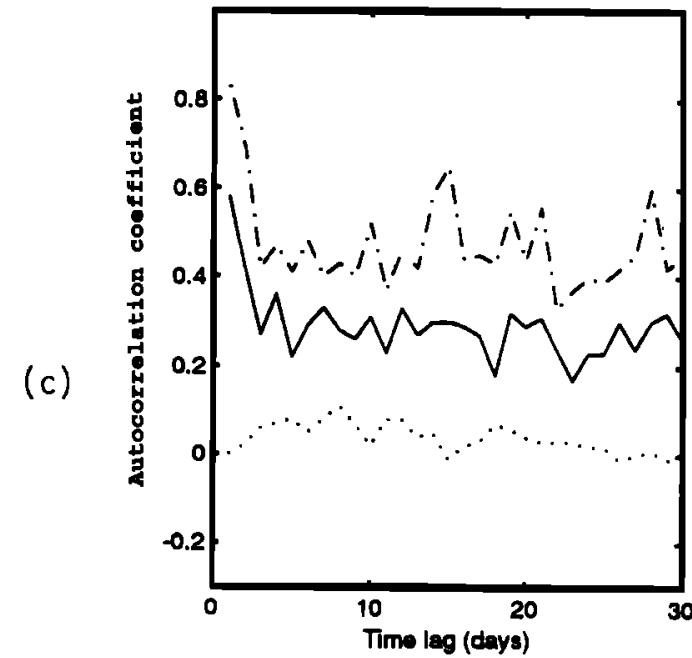

Figure 15. Summer temporal variation of ACF at different spatial lags: $m=0$ (no lag, dash-dotted line), $m=1(10-\mathrm{km} \mathrm{lag}$, solid line), and $m=15(150 \mathrm{~km}$, dotted line) for three levels: (a) surface $(\sigma=0),(\mathrm{b})$ middepth $(\sigma=0.5)$, and (c) near bottom $(\sigma=0.8)$.

[1991]. This infers that the temperature signal in the Yellow Sea shelf is stronger than in the open waters. In both winter and summer seasons the largest noise occurs at the midlevel $(\sigma=0.5)$. This is expected since this is the transition layer where both the meteorological and topographic effects occur. The signal-to-noise ratio is greater in summer than in winter.

The vertical variation in temporal and spatial decorrelation scales is smaller in winter than in summer. In winter the temporal scale varies only a half a day and the horizontal scale changes only $14 \mathrm{~km}$ among three different levels $(\sigma=0,0.5$, 0.8 ). This vertically quasi-uniformity in decorrelation scales also represents the winter single-layer structure caused by the strong surface forcing. In winter the Yellow Sea shelf experiences strong mixing due to both strong winds and the upward buoyancy flux. With a large part of the Yellow Sea having depths less than $50 \mathrm{~m}$, vertical mixing reaches the bottom and creates isothermal profiles. Thus decorrelation scales will be similar from the surface to the near-bottom $(\sigma=0.8)$ water column. In summer the temporal scale increases 5 days and the horizontal scale decreases $94 \mathrm{~km}$ from the surface $(\sigma=0)$ to the near-bottom $(\sigma=0.8)$ waters. This vertically varying decorrelation scale also implies the summer multilayer structure.

Surface horizontal decorrelation scales are almost $100 \mathrm{~km}$ longer in summer than in winter. This is due to the strong solar heating in summer, causing a relatively uniform SST field. Surface temporal decorrelation scales are 2.4 days shorter in summer than in winter. This might be caused by the shallower surface mixed layer in summer (less thermal inertia). Only the upper layer water is affected in summer by the atmospheric forcing rather than the entire water column as in winter. The surface temporal decorrelation scale should be shorter in summer than in winter.

An interesting feature shown in Table 3 is the increase of temporal decorrelation scale with depth in both summer (evident) and winter (slight). The near-bottom water $(\sigma=0.8)$ has the longest temporal scale in summer, which could be directly related to the existence of the Yellow Sea Cold Water throughout the summer in the middle of the Yellow Sea. 
(a)

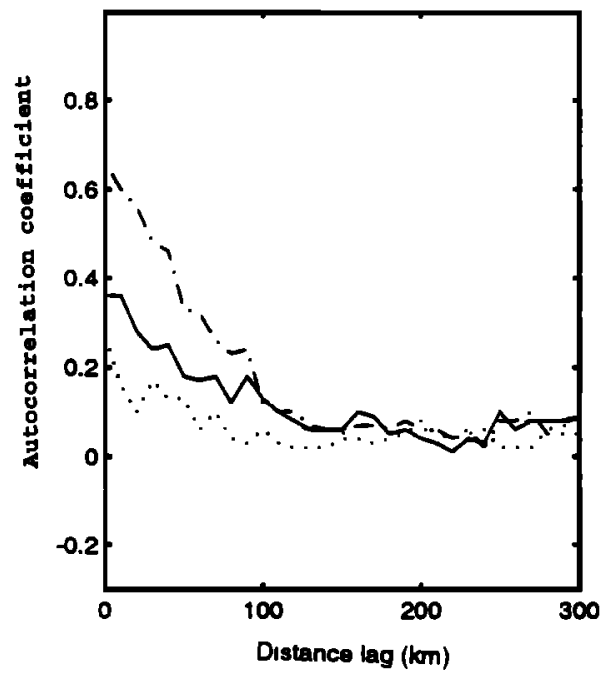

(b)

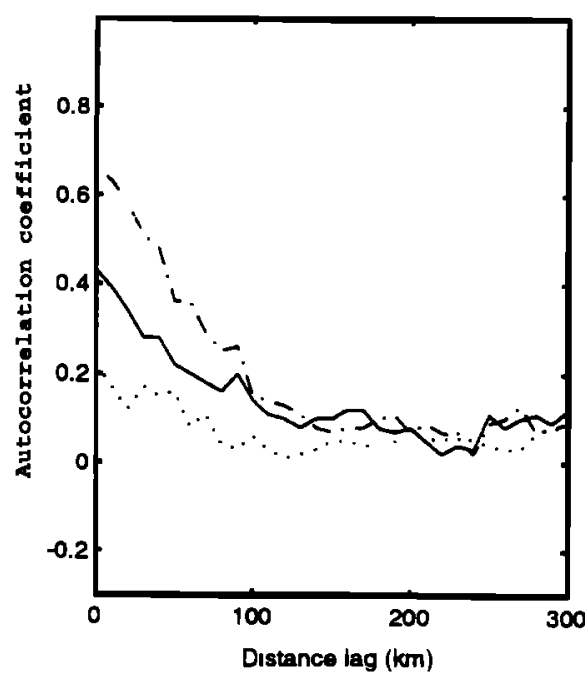

(c)

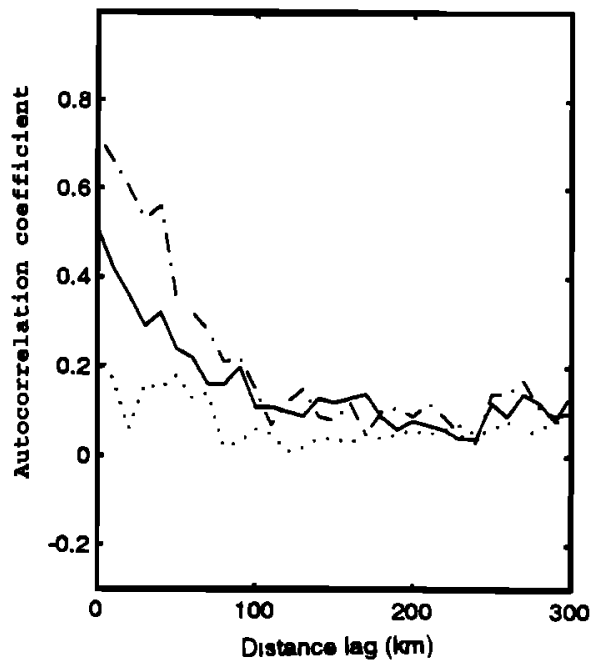

Figure 16. Winter spatial variation of ACF at different temporal lags: $n=0$ (no lag, dash-dotted line), $n=$ 1 (1-day lag, solid line), and $n=15$ (15-day lag, dotted line) for three levels: (a) surface $(\sigma=0)$, (b) middepth $(\sigma=0.5)$, and (c) near bottom $(\sigma=0.8)$.

\section{Applications}

\subsection{Optimum Interpolation}

Optimum interpolation assigns a weight to each observation that accounts for variation in spatial and temporal sampling. The interpolated temperature anomaly at the grid point, $T_{G}^{\prime}$, is a linear combination of the observed anomalies, $T_{1}^{\prime}, T_{2}^{\prime}, T_{N}^{\prime}$ with weights $\alpha_{1}, \alpha_{2}, \cdots, \alpha_{N}$

$$
T_{G}^{\prime}=\sum_{i=1}^{N} \alpha_{i} T_{\imath}^{\prime}
$$

The values of the weights, $\alpha_{t}(i=1,2, \cdots, N)$, are found by minimizing, in a least squares sense, the difference between the interpolated value at the grid node and the true value there and obtained from solving the algebraic equations [Gandin, 1965]:

$$
\sum_{j=1}^{N} \alpha_{\jmath} \mu_{t j}+\lambda^{-2} \alpha_{t}=\mu_{G t}
$$

where $i=1,2, \cdots, N$. Here $\lambda$ is the signal-to-noise ratio, $\mu_{\text {t }}$ is the autocorrelation between locations $i$ and $j$, and $\mu_{G l}$ is the autocorrelation between the grid node and location $i$,

$$
\mu_{t}=\eta\left(m_{t}, n_{l}\right), \quad \mu_{G t}=\eta\left(m_{G l}, n_{G t}\right)
$$

where $\left(m_{\imath}, n_{\imath j}\right)$ and $\left(m_{G i}, n_{G i}\right)$ represent spatial and temporal separations between locations $i$ and $j$ and between location $i$ and the grid node, respectively. For each grid node location, (10) results in a set of $N$ linear algebraic equations to be solved for $N$ unknowns, $\alpha_{\iota}$, by matrix inversion. In (10) the autocorrelations $\mu_{i j}$ and $\mu_{G}$, and the signal-to-noise ratio $\lambda$ have been computed at three levels $(\sigma=0,0.5,0.8)$ from the MOODS data set. Therefore for these levels the $N$ weights $\alpha_{i}$ can be determined by solving (10), and therefore any new observations $T_{1}^{\prime}, T_{2}^{\prime}, \cdots, T_{N}^{\prime}$ can be interpolated into any grid node $G$.

To run the U.S. Navy's OTIS, the temporal and spatial decorrelation scales $A_{\sigma}^{-1}$ and $C_{\sigma}^{-1}$ should be prescribed [Phoebus, 1988; Clancy, 1983]. Table 3 provides useful information for assigning these values for the Yellow Sea OTIS model. 
(a)
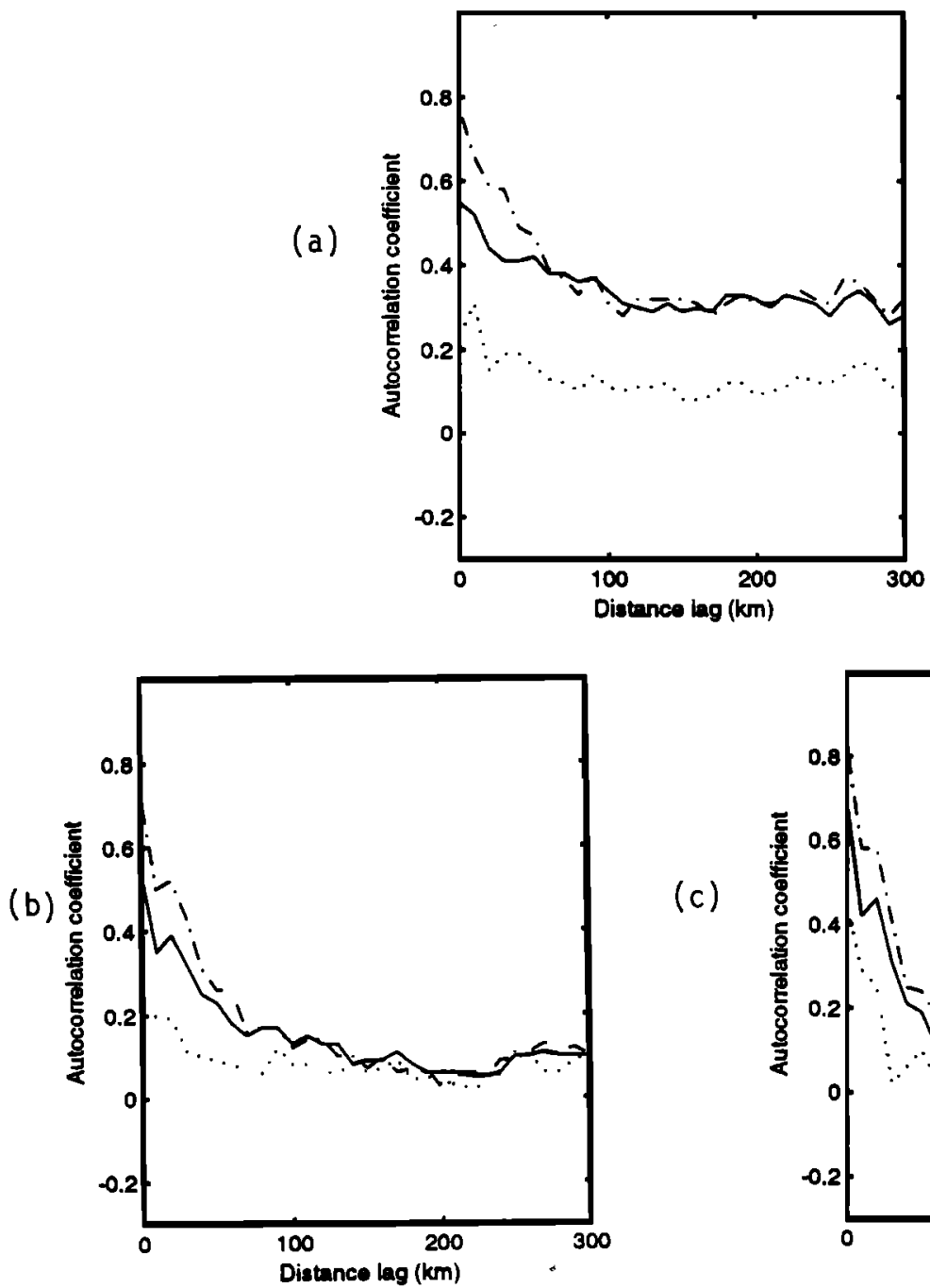

(c)

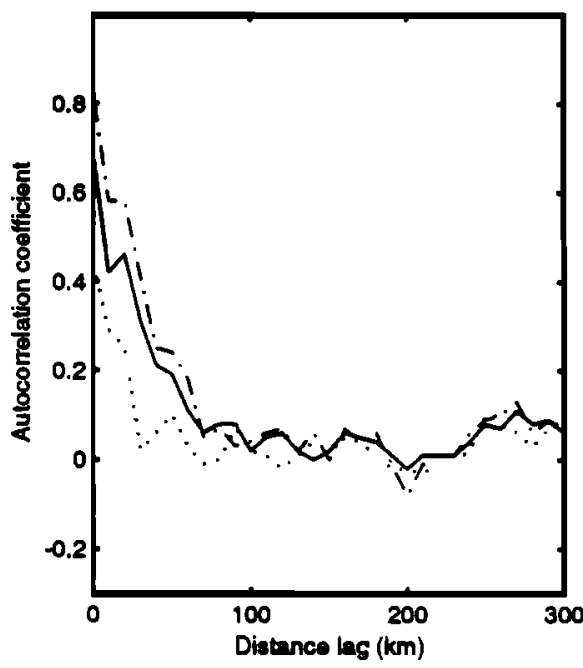

Figure 17. Summer spatial variation of $\mathrm{ACF}$ at different temporal lags: $n=0$ (no lag, dash-dotted line), $n=1$ (1-day lag, solid line), and $n=15$ (15-day lag, dotted line) for three levels: (a) surface $(\sigma=0),(\mathrm{b})$ middepth $(\sigma=0.5)$, and (c) near bottom $(\sigma=0.8)$.

\subsection{Observational Network Design}

The temporal and horizontal decorrelation scales are useful for an optimal observational network design. As we mentioned in section 6.3, the noise comes from instrumental and geophysical errors. Since the instrumental error in expendable bathythermograph (XBT) measurements is usually about $0.1^{\circ} \mathrm{C}$ [Barnett and Bernstein, 1980] and is even smaller in conductivity-temperature-depth (CTD) measurements, the instrumental error is generally neglected against the geophysical error. This implies that the curtailment of noise must be accomplished by the reduction of geophysical error. This is usually done by increasing the sample density. Having determined the statistical structure of thermal variability in the Yellow Sea shelf, the

Table 2. The $f$ Values of the Yellow Sea ACF Estimations

\begin{tabular}{ccc}
\hline & Winter & Summer \\
\hline Surface & 28.64 & 12.26 \\
0.5 & 26.43 & 11.71 \\
0.8 & 25.01 & 11.34 \\
\hline
\end{tabular}

minimum sampling density required to detect thermal variability can now be arbitrated as two or three samples per decorrelation scale [Sprintall and Meyers, 1991]. This would mean that spatially, any temperature measurement in both summer and winter may be conducted at $50-80 \mathrm{~km}$ and $4-6$ day intervals with the knowledge that the subsurface features will also be adequately sampled.

Table 3. Seasonal and Vertical Variations of Decorrelation Scales

\begin{tabular}{lcccc}
\hline Season & Depth & $\begin{array}{c}\text { Temporal } \\
\text { Decorrelation } \\
\text { Scale, } \\
\text { days }\end{array}$ & $\begin{array}{c}\text { Spatial } \\
\text { Decorrelation } \\
\text { Scale, } \\
\mathbf{k m}\end{array}$ & $\begin{array}{c}\text { Signal-to- } \\
\text { Noise } \\
\text { Ratio } \\
(\lambda)\end{array}$ \\
\hline Winter & surface & 14.7 & 158 & 2.06 \\
& $50 \%$ & 14.7 & 167 & 1.88 \\
Summer & $80 \%$ & 15.2 & 172 & 2.21 \\
& surface & 12.3 & 251 & 3.0 \\
& $50 \%$ & 15.8 & 169 & 2.21 \\
& $80 \%$ & 17.2 & 157 & 3.0 \\
\hline
\end{tabular}




\section{Conclusions}

1. The computation of ACF for $\sigma$ levels proposed in this paper demonstrates a good capability to obtain the statistical structure of the continental shelf thermal field. After the statistical structures for several $\sigma$ levels were constructed from 35,658 profiles (1929-1991) on the Yellow Sea shelf from the MOODS database, we obtain the temporal and spatial decorrelation scales and their seasonal and vertical variations for the Yellow Sea shelf thermal fields. These are important for optimum interpolation; for example, the decorrelation scales are crucial for running the U.S. Navy's OTIS model.

2. The signal-to-noise ratios for both winter and summer are quite high. This infers that the temperature signal in the Yellow Sea shelf is strong. In both the winter and summer seasons the largest noise occurs at the midlevel $(\sigma=0.5)$. The signal-to-noise ratio is greater in summer than in winter.

3. The vertical variation in temporal and spatial decorrelation scales is smaller in winter than in summer. In winter the temporal scale varies only a half a day and the horizontal scale changes only $14 \mathrm{~km}$ among three different levels $(\sigma=0,0.5$, 0.8 ). This vertical quasi-uniformity in decorrelation scales also represents the winter single-layer structure caused by the strong surface cooling and stirring. In summer the temporal scale increases 5 days and the horizontal scale decreases $94 \mathrm{~km}$ from the surface $(\sigma=0)$ to the near-bottom $(\sigma=0.8)$ waters. This vertically varying decorrelation scale also implies the summer multilayer structure.

4. The seasonal variation in temporal and spatial decorrelation scales has its maximum at the surface, reduces with depth to a minimum at midlevel $(\sigma=0.5)$, and then enhances with depth to the near-bottom level. The surface horizontal decorrelation scales are almost $100 \mathrm{~km}$ longer in summer than in winter. This is due to the strong solar heating in summer, causing a relatively uniform SST field. Surface temporal decorrelation scales are 2.4 days shorter in summer than in winter. This might be caused by the shallower surface mixed layer in summer (less thermal inertia).

5. The temporal decorrelation scale increases with depth in both summer (evident) and winter (slight). The near-bottom water $(\sigma=0.8)$ has the longest temporal scale in summer, which could be directly related to the existence of the Yellow Sea Cold Water (YSCW) throughout the summer in the middle of the Yellow Sea.

6. The temporal and horizontal decorrelation scales are useful for designing an optimum observational network. The minimum sampling density required to detect thermal variability in the Yellow Sea shelf would be $50-80 \mathrm{~km}$ and $4-6$ day intervals per temperature measurement with the knowledge that the subsurface features will also be adequately sampled. work was funded by the Naval Oceanographic Office, the Office of Naval Research NOMP and PO Programs, and the Naval Postgraduate School.

\section{References}

Barnett, T. P., and R. L. Bernstein, Expandable measuring devices, in Air-Sea Interaction, edited by F. Dobson, L. Hasse, and R. Davis, pp. 387-398, Plenum, New York, 1980.

Bartz, P., South Korea, Oxford Univ. Press, New York, 1972.

Blumberg, A. F., and G. L. Mellor, A description of a threedimensional coastal ocean circulation model, in Three-Dimensional Coastal Ocean Models, Coastal Estuarine Stud., vol. 4, edited by N. S. Heaps, pp. 1-16, AGU, Washington, D. C., 1987.

Clancy, R. M., The effect of observational error correlations on objective analysis of ocean thermal structure, Deep Sea Res., Part A, 30(9), 985-1002, 1983.

Elms, J. D., U.S. Navy regional climatic study of the central east Asian coast and associated waters, Rep. NAVAIR 50-1C-556, U.S. Nav. Oceanogr. Command, Stennis Space Cent., Miss., 1990.

Gandin, L. S., Objective Analysis of Meteorological Fields, 242 pp., Isr. Program for Sci. Transl., Jerusalem, 1965.

Guan, B. X., Patterns and structures of the currents in the Bohai, Huanghai, and East China Seas, in Oceanology of China Seas, edited by Y. Liang and C. K. Tseng, pp. 17-26, Kluwer Acad., Norwell, Mass., 1994.

Hsueh, Y., Recent current observations in the eastern Yellow Sea, $J$. Geophys. Res., 93, 6875-6884, 1988.

Langill, R. H., Forecasting guide for the Republic of Korea, Det. 18, 215 pp., 20th Weather Squadron, 1st Weather Wing, U.S. Air Force, San Francisco, Calif., 1976.

$\mathrm{Li}, \mathrm{H}$., and $\mathrm{Y}$. Yuan, On the formation and maintenance mechanisms of the cold water mass of the Yellow Sea, Chin. J. Oceanol. Limonol., 10(2), 97-106, 1992.

MATLAB, Reference Guide, Math Works, Natick, Mass., 1992.

Ozsoy, E., A. Hecht, and U. Unluata, Circulation and hydrology of the Levantine Basin, Prog. Oceanogr., 22, 125-170, 1989.

Phoebus, P. A., Improvements to the data selection algorithms in the Optimum Thermal Interpolation System (OTIS), Rep. 239, Nav. Ocean Res. and Dev. Activ., Stennis Space Cent., Miss., 1988.

Sprintall, J., and G. Meyers, An optımal XBT sampling network for the eastern Pacific Ocean, J. Geophys. Res., 96, 10,539-10,552, 1991.

Van Loon, H., Climates of the oceans, World Surv. Climatol., 15, 453-458, 1984.

Walpole, R. E., and R. H. Myers, Probabilty and Statustics for Engineers and Scientists, 4th ed., 765 pp., Macmillan, Indianapolis, Ind., 1989.

Wells, S. K., Temporal and spatial decorrelation scales of the Yellow Sea thermal fields, M.S. thesis, 98 pp., Naval Postgrad. School, Monterey, Calif., 1994.

White, W. B., G. Meyers, and K. Hasunuma, Space/time statistics of short-term climatic variability in the western North Pacific, $J$. Geophys. Res., 87, 1979-1989, 1982.

M. Carron, S. D. Haeger, and C. Szczechowski, Naval Oceanographic Office, Stennis Space Center, MI 39529.

P. C. Chu and S. K. Wells, Department of Oceanography, Naval Postgraduate School, Code $\mathrm{OC} / \mathrm{Cu}$, Monterey, CA 93943-5000. (e-mall: chu@nps.navy.mıl)

(Received March 22, 1996; revised August 21, 1996; accepted October 8, 1996.)
Acknowledgments. The authors are grateful to Laura Ehret, Chenwu Fan, and Michael Cook for programming assistance. This 